\title{
Metodologias para quantificação de microplásticos nas águas do rio Cubatão do Sul, Palhoça - Santa Catarina
}

Estrabão

$\operatorname{Vol}(2): 210-219$

(C)The Author(s) 2021

DOI: $10.53455 /$ re.v2i.58

\section{Karla Viviane De Carvalho ${ }^{1}$, Claudia Lira² and Walter Martin Widmer ${ }^{2}$}

\begin{abstract}
Com o aumento da produção de plástico no mundo, a disposição deste resíduo tem sido amplamente discutida e é um dos problemas mais desafiadores do século.O uso versátil, diversificado e a produção mundial crescente fazem com que os materiais plásticos sejam largamente utilizados nos diversos segmentos. Estes materiais podem se degradar em partículas menores originando os microplásticos, onde sua disposição final indevida pode contaminar a biota dos ecossistemas. Este estudo teve como objetivo definir metodologias mais adequadas para detectar microplásticos em amostras de águas superficiais, a fim de diagnosticar a presença de microplásticos no Rio Cubatão do Sul em Palhoça. Foi realizada uma revisão de literatura das metodologias utilizadas para águas, visando definir a metodologia para este trabalho. Através desta revisão bibliográfica definiu-se adotar uma metodologia adaptada, sendo proposto um procedimento de coletas, preparação e separação de amostras, quantificação e caracterização de amostras. Não há regulamentação exigindo o monitoramento destes contaminantes, porém são extremamente necessários novos estudos que possibilitem quantificar os níveis de contaminação em nossos ambientes aquáticos. Espera-se alcançar resultados eficientes e significativos que possam contribuir com a quantificação e redução dessa forma de poluição.
\end{abstract}

\section{Keywords}

Água, Ambiente, Plásticos 


\section{Introduction}

Com o aumento da produção de plástico no mundo, a sua disposição final tem sido amplamente discutida e se tornou um grande problema ambiental que apresenta inúmeros efeitos negativos para o meio ambiente (Martins \& Tavares, 2017). É um dos problemas mais desafiadores do século pela onipresença do plástico na vida contemporânea.

A produção mundial crescente faz com que os materiais plásticos sejam largamente utilizados nos diversos segmentos, pois seu uso é versátil e diversificado. Entretanto, diante das suas características singulares, surge uma nova e recorrente problemática, relacionada à disposição destes resíduos os quais se descartados indevidamente podem ocasionar efeitos prejudiciais para a biota dos ecossistemas e para os seres humanos.

A disposição inadequada de resíduos sólidos, podendo conter substâncias tóxicas produzidas nos grandes centros urbanos acaba, direta ou indiretamente, contaminando os ambientes aquáticos, ocasionando impactos ambientais. A maior parte das fontes de poluição plásticas estão associadas a atividades humanas em áreas urbanizadas associadas em bacias hidrográficas (Souza \& De,2020).

Os microplásticos são classificados como contaminantes emergentes, ou seja, materiais que ainda não possuem padrões legais e portanto ainda não existem rotinas estabelecidas de monitoramento nas estações de tratamento de esgoto e de água (UFLA,2020). A falta de regulamentação e metodologias específicas para investigar a presença destes poluentes estão sendo cada vez mais debatidas. Os estudos nesta área são incipientes, porém é muito importante o desenvolvimento de novas pesquisas possibilitando quantificar os níveis de contaminação nos ambientes aquáticos catarinenses. Assim, o objetivo deste trabalho é uma revisão da literatura para definir a metodologia para quantificação e caracterização dos microplásticos nas águas superficiais do Rio Cubatão do Sul em Palhoça/SC.

\section{REVISÃO BIBLIOGRÁFICA}

Os plásticos são polímeros derivados de petróleo, podendo ser de diversos tipos. Quando o material plástico é exposto a condições ambientais diversas e interação com a biota local, ele sofre fragmentação e origina detritos, chamados de microplásticos (Souza \& De, 2020).

Os microplásticos são onipresentes no ambiente e foram detectados em água marinha, esgoto, água doce, na comida, no ar e na água potável, tanto na engarrafada quanto na água de torneira (OMS, 2019). O European MSFD Working Group on Good Environmental Status (WG-GES) produziu um manual demonitoramento de lixo marinho, o qual define classes de tamanho para resíduos plásticos,

\footnotetext{
${ }^{1}$ Mestrado Profissional em Clima e Ambiente, Programa de Mestrado Profissional em Clima e Ambiente, Instituto Federal de Santa Catarina, Claudia Lira, Florianópolis, Santa Catarina

${ }^{2}$ Instituto Federal de Santa Catarina, Florianópolis, Santa Catarina

Email: claudialira@ifsc.edu.br (Claudia Lira)
}

Corresponding author:

Walter Martin Widmer, Instituto Federal de Santa Catarina, Florianópolis, Santa Catarina

Email: walter.widmer@ifsc.edu.br. 
microplásticos e nanoplásticos da seguinte forma: Macroplásticos (maior que $25 \mathrm{~mm}$ ), Mesoplásticos (de $25 \mathrm{~mm}$ até $5 \mathrm{~mm}$ ), Grandes Microplásticos (de $5 \mathrm{~mm}$ até $1 \mathrm{~mm}$ ), Pequenos Microplásticos (de $1 \mathrm{~mm}$ até $20 \mu \mathrm{m}$ ) e Nanoplásticos (menor que $20 \mu \mathrm{m}$ ).

De acordo com Caixeta e Menezes Filho (2018), nano e microplásticos podem, quando disponíveis no ambiente, interagir com os organismos através da ingestão, atravessando as barreiras biológicas, penetrando e sendo acumulados nos tecidos e órgãos. Há uma preocupação sobre os efeitos químicos das micropartículas ingeridas ou inaladas por humanos e animais, pois elas podem ser vetores de microrganismos e contaminantes, tais como metais pesados e poluentes orgânicos persistentes (Jones, Fapesp, \& Paulo, 2019).

Segundo Andrady, Anthony L. (2011), estima-se que $80 \%$ dos resíduos plásticos que chegam ao ambiente marinho têm origem de áreas continentais. Diante da potencialidade da ocorrência de problemas que os resíduos plásticos podem causar, especialmente os nano e microplásticos, é importante a utilização de métodos eficientes para sua detecção em matriz aquática.

\section{METODOLOGIA}

\section{Área de Estudo}

A área de estudo deste trabalho é o Rio Cubatão do Sul, com $65 \mathrm{Km}$ de extensão localizado na bacia hidrográfica do rio Cubatão do Sul (Fig. 1) Essa bacia hidrográfica está incluída na parte norte da unidade de conservação no Parque Estadual das Serra do Tabuleiro ocupando 33,8\% (28.300,8 hectares), sendo de grande importância ambiental e ecológica, com ecossistemas que suportam grande biodiversidade. O Parque apresenta diversas nascentes da bacia, sendo assim bastante relevante na questão de contribuição da manutenção da qualidade hídrica regional (IMA,2018).

De acordo com a SIRHESC (2017), o rio Cubatão do Sul origina-se da junção dos rios do Cedro e Bugres no município de São Bonifácio e atravessa as sedes urbanas de Águas Mornas e Santo Amaro da Imperatriz. Seu principal afluente da margem esquerda é o rio Vargem do Braço, no município de Palhoça. Na bacia do rio Cubatão do Sul vive uma população de cerca de 81.000 pessoas, destas 72.000 em áreas urbanas. O Rio Cubatão do Sul apresenta grande relevância por contemplar captação de águas para a região da Grande Florianópolis. Este manancial é responsável pelo abastecimento público da Grande Florianópolis, juntamente com o Rio Vargem do Braço (Pilões), atendendo aproximadamente 900 mil habitantes (Pmf \& Florianópolis, 2010).

O Rio Cubatão sofre com os impactos da ação antrópica que vêm gradativamente degradando tanto as margens como a qualidade e quantidade de suas águas. Atualmente o Cubatão é a principal alternativa da CASAN em períodos de estiagens e secas, pois o Rio Vargem do Braço não possui vazão suficiente, sendo extremamente afetado nestes períodos (CASAN,2020).

De acordo com Loch (2019) o Rio Cubatão do Sul, vem desde a sua nascente com maior interferência antrópica em suas margens, principalmente por se localizar a áreas mais próximas ao centro de cidades, como Águas Mornas, Santo Amaro da Imperatriz e Palhoça. A maior ocupação populacional à montante da captação de água da CASAN pertence ao município de Santo Amaro da Imperatriz com aproximadamente 20.000 habitantes (Ibge, Panorama, \& Censo, 2010), e desenvolve principalmente atividades agrícola e pecuária. Os municípios também geram despejos domésticos, bem como desenvolvem atividades extrativistas de areia e argila da calha e das margens do Rio Cubatão do Sul (Sergio \& Zechner, 2012). 


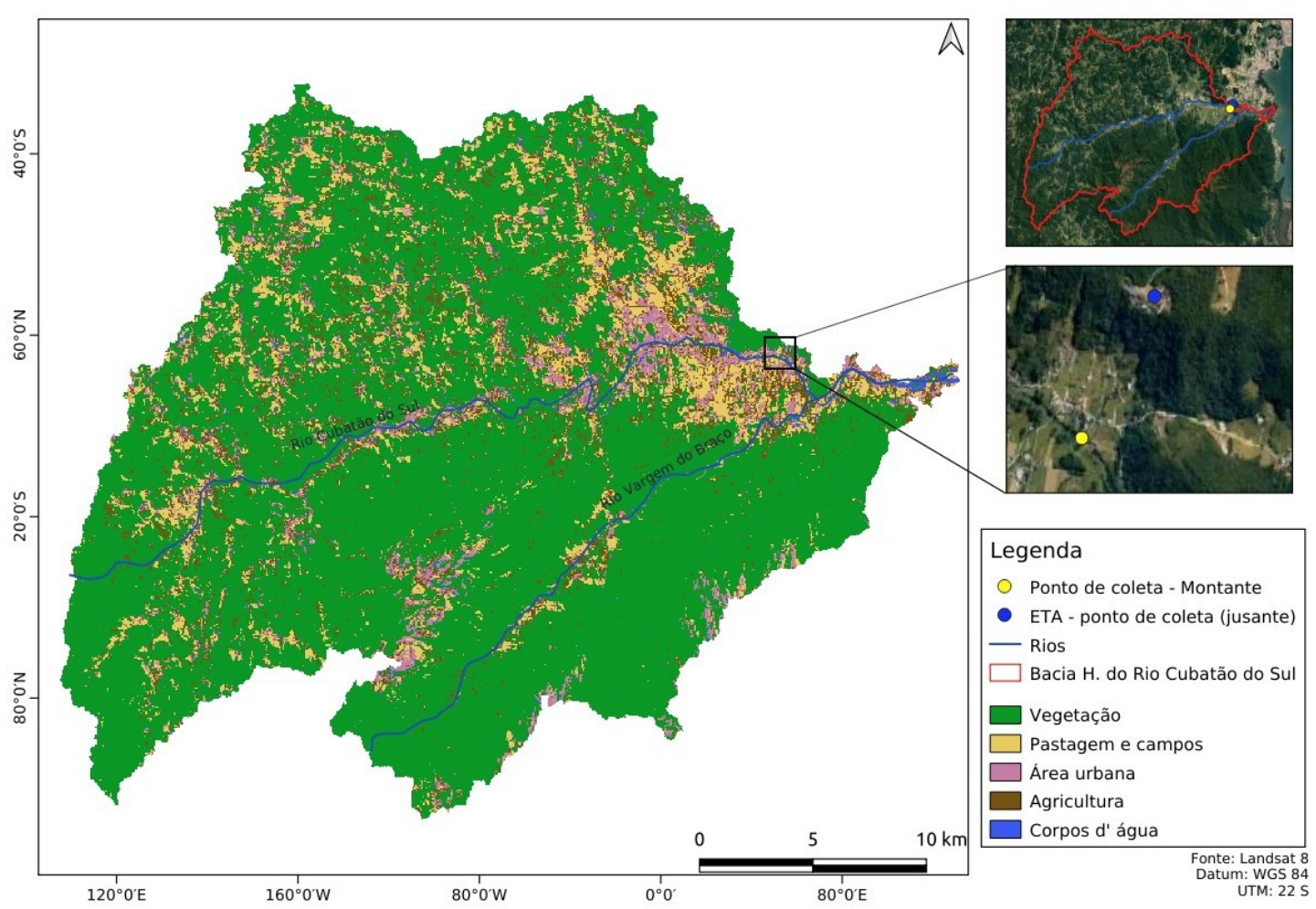

Figure 1. Mapa da localização do Rio Cubatão do Sul na Bacia Hidrográfica do Rio Cubatão do Sul. A direita acima de delimitada pela linha vermelha está o perímetro da bacia hidrográfica e a direita abaixo os pontos de coleta destacados em azul (ETA Cubatão - Saída de Tratamento) e amarelo (a montante da Captação de água da CASAN) em Palhoça, SC.

\section{Escolha demetodologia}

Para alcançar o objetivo apresentado, foi feita uma revisão de literatura através de consultas em trabalhos acadêmicos disponíveis no meio científico publicados entre 2014 e 2020 . As referências foram selecionadas nas bases eletrônicas de dados: periódicos da Coordenação de Aperfeiçoamento de Pessoal de Nível Superior (Capes) e Google Scholar. A escolha das literaturas foi feita a partir da leitura dos títulos e resumos, sendo selecionadas as que melhor contemplaram o tema proposto. A revisão foi realizada no período de agosto a outubro de 2021. Com base nos artigos estudados foram selecionados seis trabalhos que abordaram amostragem e análises de microplásticos em água (doce e marinha) para revisão dos métodos e elaboração de uma proposta metodológica para o estudo a ser realizado no Rio Cubatão do Sul em Palhoça.

A metodologia proposta resultou de uma adaptação, que foi feita a partir da leitura e comparação dos trabalhos selecionados conforme ilustrado na tabela 1. Visando buscar melhor eficiência para os ensaios 
futuros, foi investigada a viabilidade e eficiência na identificação dos microplásticos em amostras de água doce.

Table 1. Metodologias empregadas em estudos sobre microplásticos em matrizes de água

\begin{tabular}{|c|c|c|c|}
\hline Referências & Metodologias & Resultados & Local \\
\hline Ivar do Sul et al. (2014) & $\begin{array}{l}\text { Coleta de amostras com } \\
\text { arrasto superficial utilizando } \\
\text { rede de plâncton, filtrando- } \\
\text { se os resíduos coletados } \\
\text { e caracterizados por } \\
\text { microscopia. }\end{array}$ & $\begin{array}{l}\text { Predominância de fragmen- } \\
\text { tos de microplásticos. }\end{array}$ & $\begin{array}{l}\text { Pernambuco: Arquipélago de } \\
\text { São Pedro e São Paulo }\end{array}$ \\
\hline Lima et al. (2014) & $\begin{array}{l}\text { Coleta de amostras com } \\
\text { arrasto superficial utilizando } \\
\text { rede de plâncton, filtrando- } \\
\text { se os resíduos coletados } \\
\text { e caracterizados por } \\
\text { microscopia }\end{array}$ & $\begin{array}{l}\text { O estudo categorizou frag- } \\
\text { mentos rígidos de microplás- } \\
\text { ticos }\end{array}$ & $\begin{array}{l}\text { Pernambuco: Estuário de } \\
\text { Goiânia }\end{array}$ \\
\hline Olivatto et al. (2018) & $\begin{array}{l}\text { Coleta de amostrasutilizando } \\
\text { rede de plâncton com arrasto } \\
\text { horizontal. Foram utilizadas } \\
\text { técnicas de filtração e } \\
\text { digestão oxidativa das } \\
\text { amostras e caracterizadas } \\
\text { por e espectroscopia no } \\
\text { infravermelho. Foram } \\
\text { realizadas análise elementar } \\
\text { através de microscopia e } \\
\text { utilização de software de } \\
\text { processamento digital de } \\
\text { imagens. }\end{array}$ & $\begin{array}{lrr}\text { A maioria das } & \text { amostras } \\
\text { analisadas } & & \text { foram } \\
\text { categorizadas } & & \text { como } \\
\text { fragmentos. Os } & \text { resultados } \\
\text { apresentaram } & \text { eficiência } \\
\text { e o custo de } & \text { aplicação } \\
\text { metodológica } & \text { mostrou-se } \\
\text { viável para a pesquisa }\end{array}$ & $\begin{array}{l}\text { Rio de Janeiro: Baía de } \\
\text { Guanabara }\end{array}$ \\
\hline Wang et al. (2017) & $\begin{array}{l}\text { As amostras foram tratadas } \\
\text { com digestão oxidativa. Foi } \\
\text { realizada a filtração e análise } \\
\text { microscópica eletrônica de } \\
\text { varredura. }\end{array}$ & $\begin{array}{l}\text { Detectado microplásticos } \\
\text { coloridos e elevada presença } \\
\text { de fibras. Mais de } 80 \% \text { dos } \\
\text { microplásticos tinham um } \\
\text { tamanho }<2 \mathrm{~mm} \text {. }\end{array}$ & China: Wuhan \\
\hline
\end{tabular}


Table 1 continued

Rodrigues et al. (2018)

Oliveira (2020)
As amostras passaram por processos de peneiramento, oxidação de peróxido úmido com adição de cloreto de zinco e filtração a vácuo. Separação por densidade e identificados por estereomicroscópio Optika e espectroscopia no infravermelho transformada de Fourier

Coletas com grande volumes de amostra e diferença de profundidades, realizadas com auxílio de peneiras de malhas diversas e uso de bomba d'água. Gravimetria para separação de amostras. Preparação com peróxido de hidrogênio e Sulfato de Ferro II. Foram fotografadas as amostras e quantificadas e classificadas com auxílio de software para processamento de imagens e identificadas com espectroscopia no infravermelho.
Foram detectados microplásticos em todas as amostras analisadas. De um total de 43 amostras, 34 foram identificadas como polímeros sintéticos, 3 foram identificados como não plásticos e 6 não foi conclusivo a identificação

Coletas com grande volumes de amostra e diferença de profundidades, realizadas com auxílio de peneiras de malhas diversas e uso de bomba d'água. Gravimetria para separação de amostras. Preparação com peróxido de hidrogênio e Sulfato de Ferro II. Foram fotografadas as amostras e quantificadas e classificadas com auxílio de software para processamento de imagens e identificadas com espectroscopia no infravermelho.

Portugal: São João da Madeira, Aguincheira e Estarreja (Rio Antuã)

Campo Grande, MS: Lago do

\section{Amor}


Através das leituras das metodologias mais utilizadas de amostragem, quantificação e caracterização de microplásticos descritas nos artigos, foi definida uma proposta de metodologia adaptada para ser aplicada no presente estudo das águas do rio Cubatão do Sul. Os critérios utilizados foram a viabilidade econômica aliada à eficiência dos resultados.

A metodologia adaptada para o estudo a ser realizado no Rio Cubatão do Sul resultou na proposta com as seguintes etapas: as amostras serão coletadas em dois pontos, sendo um na entrada da captação de água bruta da CASAN em Palhoça conforme Figura 2 e outro pós-tratamento, para efeitos comparativos. Serão utilizadas redes de plâncton de arrasto horizontal, baldes de inox e peneiras de aço (malha de $355 \mu \mathrm{m}$ e malha de $475 \mathrm{~mm}$ ). Para preservação e remoção da matéria orgânica será utilizado a solução Peróxido de Hidrogênio 35\% + Sulfato de Ferro II 0,05M.Os microplásticos serão separados e classificados por tamanho, forma e cor e para análise qualitativa será utilizado o método de espectrofotometria no infravermelho. 

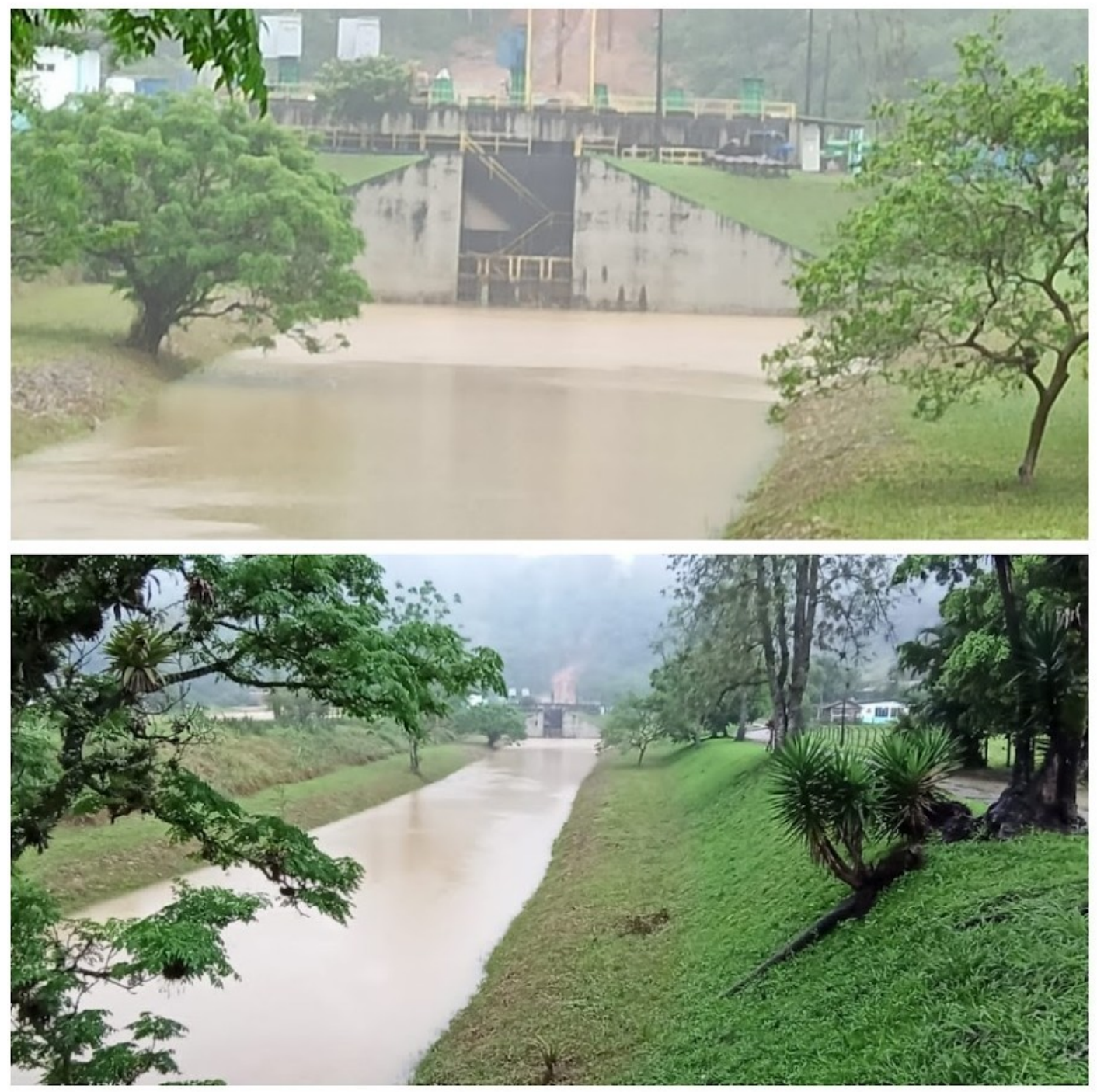

Figure 2. Entrada da captação de água bruta CASAN em Palhoça 


\section{RESULTADOS ESPERADOS}

A ausência de uma padronização é um obstáculo em estudos destes tipos, pois existem diversas metodologias propostas, algumas apresentam resultados com maior eficiência, porém requerem maior complexidade de execução, bem como são economicamente inviáveis.

Não foram encontradas na literatura pesquisas deste gênero na área de estudo, sendo este pioneiro na quantificação e caracterização dessa forma de poluição no Rio Cubatão do Sul, não sendo necessariamente preciso a metodologia mais sofisticada existente, mas que tenham resultados significativos.

Através deste estudo pretende-se com a metodologia escolhida alcançar os objetivos do projeto, contribuindo com a quantificação e identificação de microplásticos em águas superficiais com resultados representativos que possibilitem o planejamento de ações de gestão hídrica além de futuramente investigar a variação sazonal da presença de microplásticos na água do rio e desenvolver um produto final que promova a educação ambiental a respeito do tema na região da Grande Florianópolis buscando a redução da poluição por este tipo de resíduos.

\section{Referências}

Caixeta, D. ., Caixeta, F. M., Filho, F., \& Nano, E. (2018).

Microplásticos nos Ecossistemas: impactos ambientais e efeitos sobre os organismos. Enciclopédia Biosfera, 19-34.

Catarina, S. S. D. I. D. R. H. D. E. D. S. (2017). Retrieved from http://www . aguas.sc.gov . br/ base-documental/bacias-hidrograficas-do-estado. Acessoemllout .2021

Da, O. M., \& Saúde. (2019). Retrieved from https: / / apps. who.int/iris/bitstream/ handle/10665/326499/9789241516198-eng.pdf?ua=1.Acessoem

(2020). Retrieved from https://ufla.br/noticias/pesquisa/13322 -microplasticos-saiba-o-que-sao-e-como-um-estudo-pioneiro-da. Acessoem

(2018). Retrieved from https://www.ima.sc.gov.br/index.php/biodiversidade/ unidades-de-conservacao/parque-estadual-da-serra-do-tabuleiro . Acessoem

Ibge, Panorama, \& Censo. (2010). Retrieved from https://cidades.ibge.gov.br/brasil/ sc/santo-amaro-da-imperatriz/panorama. Acessoem

Ivar, Sul, J., \& Assunção. (2014). Abrolhos e trindade. 2014. 75 f. tese (doutorado) - curso de pósgraduação em oceanografia. Recife. Retrieved from https://repositorio.ufpe.br/ bitstream/123456789/18853/1/TESE_Juliana\%20Ivar\%20do\%20Sul_SEM응 20assinaturas.pdf. Acessoem

Jones, F., Fapesp, S. A. D. M. R. P., \& Paulo. (2019). (Vol. 281). Retrieved from https://revistapesquisa.fapesp.br/wp-content/uploads/2019/07/ 025-028_CAPA_Pl。C3\%A1stico_281-Parte-2.Acessoem

Leite, J. G., \& Castilho. (2019). Retrieved from https : / / www . consumidormoderno.com.br/ $2019 / 08 / 26 / \mathrm{microplasticos-agua-potavel.} \mathrm{Acessoem}$ 
Lima, A. R. A. (2014). Distribution patterns of microplastics within the plankton of a tropical estuary. Environmental Research, 132, 146-155.

Loch, J. (2019). A influência da precipitação na turbidez das Águas dos rios cubatão do sul e vargem do braço sc. 2019. $95 \mathrm{f}$. dissertação (mestrado) - curso de mestrado em clima e ambiente. Florianópolis. Retrieved from https://repositorio.ifsc.edu.br/bitstream/ handle/123456789/1076/Dissertac\%CC\%A7a\%CC\%830. JulianaLoch assinaturas.pdf? sequence $=1 \& i$ sAllowed $=y$

Martins, M. C., \& Tavares. (2017). Retrieved from http://www.puc-rio.br/pibic/ relatorio_resumo2017/relatorios_pdf/ctc/QUI/QUI-Maria20Clara\% 20 Tavares $\frac{\overline{2}}{2} 20$.

Olivatto, G., \& Peregrina. (2017). Retrieved from https: //www . maxwell.vrac.puc-rio.br/ 29926/29926.pdf. Acessoem:21set. 2021

Olivatto, G. P. (2018). Microplastics: contaminants of global concern in the anthropocene. Revista Virtual de Química. Sociedade Brasileira de Química (SBQ, 1-2021.

Pmf, P., \& Florianópolis, M. D. (2010). Retrieved from http://portal .pmf.sc.gov.br/arquivos/arquivos/pdf/06_06_2012_14.30.47 $.226 a 141$ fe7934e1bb87d01822392dd65.pdf. Acessoem

Rodrigues, M. O. (2018). Spatial and temporal distribution of microplastics in water and sediments of a freshwater system (Vol. 633). Antuã River, Portugal: Elsevier BV. Retrieved from https://www.sciencedirect.com/science/article/abs/pii/ S0048969718309926?viaะ3Dihub. Acessoem:10out. 2021

Sergio, D., \& Zechner. (2012). Modelagem hidrológica da bacia do rio cubatão do sul com modelo swat. 2012. 120 f. tcc (graduação) - curso de engenharia sanitária e ambiental, centro tecnológico. Florianópolis. Retrieved from https://repositorio.ufsc.br/xmlui/bitstream/ handle/123456789/125090. Acessoem

Souza, G., \& De, R. (2020). Avaliação da presença de microplásticos em efluente gerado por estação de tratamento de esgoto (ete). 2020. $112 \mathrm{f}$. dissertação (mestrado) - curso de pósgraduação em ciências do ambiente e sustentabilidade na amazônia, ciências do ambiente. Manaus. Retrieved from https://tede.ufam.edu.br/bitstream/tede/7809/2/ Dissertaㄷ3\%a7\%c3a30_GleiceSouza_PPGCASA.pdfAcessoem:21set.2021

Wang, W. (2016). (Vol. 575). 